\title{
PENGARUH MODEL PEMBELAJARAN KOOPERATIF TIPE MAKE A MATCH BERBANTUAN MEDIA AUDIO VISUAL TERHADAP HASIL BELAJAR IPS SEKOLAH DASAR
}

\author{
I Ketut Gading 1,*, Kadek Dian Kharisma ${ }^{2}$ \\ 1 Jurusan Bimbingan Konseling. Universitas Pendidikan Ganesha, Indonesia \\ 2Jurusan Pendidikan Guru Sekolah Dasar. Universitas Pendidikan Ganesha, Indonesia
}

\begin{abstract}
This research aims to know the differences of social science learning outcomes between groups of students who got the treatment model of learning Make A Matchassisted audio visual with a group of students who did not receive treatment with a model of learning Make A Match-assisted audio visual. This research includes research of artificial experiments that use of non-equivalent design posttest only control group design. As many as 32 students SDN 3 Pacung entangled as a group of experiments and 32 students SDN 1 Pacung entangled as the control group. Experimental treatment given to groups of models of cooperative learning types make a match for a month as much as 8 times. While the control group dibelajarkan with learning that naturally occurs in the treatment group of experiments underway. Student learning outcomes data collected through methods of tests with a test instrument shaped as a multiple choice question. Collected data were analyzed by descriptive statistics and statistical infirensial test-t. The results of this study found that there is a difference between the social science study results of students who got the treatment model of learning Make A Match of audio visual and assisted the Group of students who did not receive the treatment model of learning Make A Matchassisted audio visual on IPS subjects class IV. This is demonstrated by the results of significant value $<0.05$ then $\mathrm{H} 1$ accepted and $\mathrm{H} 0$ is rejected and an average score of experimental group students i.e. 23.28 and score an average control group i.e 15.00. This means experimental > control, so that it can be concluded the implementation of cooperative learning model types Make A Match using the media audio visual effect on the results of studying social science at grade IV.
\end{abstract}

\section{Keywords:}

Make A Match, Audio

Visual, Learning

Outcomes, and Social

Knowledge.

\section{Pendahuluan}

Di zaman era globalisasi seperti dewasa ini, teknologi IPTEK berkembang semakin maju sehingga pendidikan juga dituntut semakin berkualitas. Pendidikan merupakan perbuatan manusiawi. Pendidikan lahir dari pergaulan antar orang dewasa dan orang yang belum dewasa dalam suatu kesatuan hidup. Mendidik yang dilakukan oleh pendidik dengan sengaja didasari oleh nilai-nilai kemanusiaan. Tindakan tersebut menyebabkan orang yang belum dewasa menjadi dewasa dengan memiliki nilai-nilai kemanusiaan dan hidup menurut nilai-nilai tersebut. Kedewasaan diri merupakan tujuan pendidikan yang hendak dicapai melalui perbuatan atau tindakan pendidikan. Langeveld (dalam Hasbullah, 2012) mengemukakan pendidikan ialah setiap usaha, pengaruh, perlindungan dan bantuan yang diberikan kepada anak tertuju kepada pendewasaan anak atau lebih tepat membantu anak agar cakap untuk melakukan tugasnya sendiri.

Menurut UU No. 20 tahun 2003 (dalam Hasbullah, 2012) bahwa, pendidikan adalah usaha sadar dan terencana untuk mewujudkan suasana belajar dan proses pembelajaran agar peserta didik secara aktif mengembangkan pontensi dirinya untuk memiliki kekuatan spiritual keagamaan, pengendalian diri, kepribadian, kecerdasan, akhlak mulia, serta keterampilan yang diperlukan dirinya, masyarakat, bangsa dan negara. Sehingga pendidikan sangat penting, sebab tanpa pendidikan manusia akan sulit berkembang dan bahkan akan semakin terbelakang. Dengan demikian pendidikan harus diarahkan untuk

\footnotetext{
* Corresponding author.

E-mail Addresses: ketutgading35gmail.com (I Ketut Gading), dian.karisma@yahoo.com (Kadek Dian Kharisma)
} 
menghasilkan manusia yang berkualitas dan mampu bersaing serta memiliki budi pekerti yang luhur dan moral yang baik.

Namun masalah kualitas pendidikan saat ini masih perlu memperoleh perhatian khusus dari para ahli pendidik karena sampai sekarang kualitas pendidikan masih dirasakan rendah. Kegiatan pembelajaran merupakan aktivitas yang paling penting dalam upaya keseluruhan pendidikan. Susanto (2013) mengemukakan bahwa pembelajaran merupakan proses untuk membantu peserta didik agar dapat belajar dengan baik. Perbaikan kualitas pembelajaran tidak terlepas dari peran guru dalam memilih strategi pembelajaran yang sesuai untuk terciptanya suasana belajar yang kondusif, sehingga dapat meningkatkan pemecahan masalah siswa dalam belajar, yang pada akhirnya berdampak pada peningkatan mutu pendidikan. Dalam merancang pembelajaran, seorang guru harus memperhatikan tujuan pembelajaran yang hendak dicapai, termasuk dalam pembelajaran IPS.

Hasil observasi yang dilakukan pada tanggal 8 Januari 2017 di SDN Gugus V kecamatan Tejakula Kabupaten Buleleng, ada beberapa hal yang dapat menyebabkan rendahnya aktivitas belajar dan hasil belajar siswa pada mata pelajaran IPS diantaranya: (1) dalam proses pembelajaran guru lebih banyak menggunakan metode ceramah, tidak menerapkan model pembelajaran yang inovatif sehingga pembelajaran menjadi pasif; (2) dalam pembelajaran siswa hanya mendengar, mencatat, dan menghafal materi yang disampaikan oleh guru. Kurangnya pemahaman guru dalam memilih dan menerapkan model pembelajaran yang dapat mengaktifkan aktivitas siswa, hal ini dilihat dari RPP yang telah dibuat oleh guru langkah pembelajaran cenderung sama dalam satu gugus, dalam RPP yang dibuat oleh guru hanya menggunakan metode ceramah dan tanya jawab sehingga dalam proses pembelajaran siswa kurang aktif serta sering merasa bosan dalam mengikuti pelajaran IPS; (3) kurangnya antusiasme siswa dalam mengikuti kegiatan pembelajaran. Berdasarkan observasi proses pembelajaran di kelas, siswa kurang diberi kesempatan mengemukakan pendapat serta siswa tidak mendapat kesempatan secara merata untuk menjawab pertanyaan dari guru; (4) kurangnya kerjasama siswa dalam kelompok, hal tersebut dapat diamati pada saat proses pembelajaran, tugas kelompok cenderun hanya salah satu siswa yang mengerjakannya dan; (5) guru kurang memanfaatkan media pembelajaran guru cenderung menggunakan satu buku dalam proses pembelajaran. Sehingga proses pembelajaran seperti yang di atas kurang mengaktifkan siswa sehingga berpengaruh pada hasil belajar siswa.

Berdasarkan hasil observasi dan pencatatan dokumen yang dilakukan pada kelas IV ditemukan bahwa hasil belajar siswa kelas IV di Gugus V Kecamatan Tejakula tergolong rendah. Hal tersebut terlihhat pada pencapaian nilai rata-rata ulangan semester mata pelajaran IPS masih dibawah Kriteria Ketuntasan Minimal (KKM) yaitu 70 yang dapat dilihat pada tabel 1. Mata pelajaran IPS mempelajari tingkah laku manusia dimasyarakat banyak aspek seperti aspek ekonomi, sikap mental, budaya, hubungan sosial, dan masih banyak aspek lainya (Suamatmadja dalam Tjandra dkk, 2005).

Tabel 1 Nilai Rata-rata Ulangan Semester I Mata Pelajaran IPS Siswa Kelas IV SDN Gugus V Kecamatan Tejakula Kabupaten Buleleng Tahun Pelajaran 2016/2017

\begin{tabular}{ccc}
\hline Nama Sekolah & Nilai Rata-rata & $\begin{array}{c}\text { Nilai Kriteria Ketuntasan } \\
\text { Minimal }\end{array}$ \\
\hline SDN 1 Pacung & 65,09 & 70 \\
SDN 2 Pacung & 66,42 & 70 \\
SDN 3 Pacung & 67,00 & 70 \\
SDN 1 Julah & 66,65 & 70 \\
SDN 2 Julah & 67,26 & 70 \\
\hline
\end{tabular}

Sebagai seorang guru dalam mendesain model pembelajaran yang memungkinkan siswa dapat berpartisipasi aktif secara fisik maupun mental, kreatif dalam meningkatkan aktivitas siswa terhadap materi yang disampaikan. Dalam hal ini guru sebagai pengarah dalam proses pembelajaran, guru berperan sebagai penyedia fasilitas da guru berperan sebagai penilai proses belajar dan hasil belajar. Hal tersebut sesuai dengan Undang-Undang Republik Indonesia No. 14 Tahun 2005 tentang Guru dan Dosen Pasal 10 ayat (1) disebutkan bahwa "kompetensi guru sebagaimana dimaksud dalam pasal 8 meliputi kompetensi pedagogik, kompetensi kepribadian, kompetensi sosial, dan kompetensi professional yang diperoleh melalui pendidikan profesi". Artinya sebagai guru harus memiliki kemampuan dan kompeten dalam bidangnya dan menguasai dengan baik bahan yang akan diajarkan.

Mengacu pada permasalahan tersebut, perlu dilakukan perubahan pembelajaran agar pembelajaran menjadi lebih menyenangkan bagi siswa. Dalam hal ini, sangat diperlukan penggunaan suatu model pembelajaran yang inovatif, sehingga siswa dapat mengkonstruksi pengetahuan sendiri. Siswa harus dianggap sebagai subjek belajar yang harus mencari dan mengkonstruksi pengetahuan sendiri, sehingga terwujud pemahaman konsepnya. Di samping itu, pembelajaran juga harus 
memberdayakan siswa semaksimal mungkin agar mereka ikut aktif dalam proses pembelajaran. Peran aktif mereka akan menggiring mereka memahami konsep-konsep IPS sehingga tujuan mata pelajaran IPS di SD dapat tercapai.

Upaya yang dilakukan adalah dengan menggunakan model pembelajaran kooperatif. Melihat pemahaman konsep siwa yang belum optimal, tentu diperlukan adanya langkah-langkah untuk meningkatkan pola pembelajaran. Dengan adanya model pembelajaran ini diharapkan siswa semakin aktif dalam kegiatan pembelajaran. Siswa diharapkan mampu melakukan kerja sama dalam kelompok, menghargai pendapat orang lain, mampu berkomunikasi dengan orang lain, dan mampu menumbuhkan semangat kebersamaan sebagai salah satu ciri manusia sebagai makhluk sosial.

Salah satu model pembelajaran yang sesuai dengan karakteristik tersebut adalah model pembelajaran kooperatif tipe make a match. Model pembelajaran ini merupakan salah satu model pembelajaran aktif. Model ini menekankan pada pembelajaran dalam kelompok yang saling membantu satu sama lainnya, bekerja sama menyelesaikan masalah, dan menyatukan pendapat untuk memperoleh keberhasilan yang optimal baik secara berkelompok maupun individual (Rusman, 2012). Keunggulan dari model ini menurut Lie (2008) adalah "siswa mencari pasangan sambil belajar mengenai suatu konsep atau topik, dalam suasana yang menyenangkan". Guru lebih berperan sebagai fasilitator, tidak hanya memberikan pengetahuan pada siswa namun guru juga harus membangun pengetahuan dalam pikirannya sendiri, sehingga dapat membuat siswa aktif, kreatif dan cerdas.

Model pembelajaran make a match "siswa diajak mencari pasangan sambil belajar mengenai suatu konsep atau topik dalam suasana yang menyenangkan" (Rusman, 2012). Perpaduan materi IPS dengan berbantuan media audio visual di dalam penerapan model make a match menghasilkan dasardasar pengetahuan yang mendalam sehingga tercipta proses pembelajaran yang lebih baik dan tercapai hasil belajar yang maksimal. Wati (2016) menyatakan media audio visual merupakan media yang dapat menampilkan unsur gambar dan suara secara bersamaan pada saat mengkomunikasikan pesan atau informasi.

Berdasarkan uraian latar belakang masalah di atas, maka perlu suatu perbaikan kualitas pembelajaran, untuk itu dilakukan penelitian eksperimen dengan judul "Pengaruh Model Pembelajaran Kooperatif Tipe Make A Match Berbantuan Media Audio Visual Terhadap Hasil Belajar IPS Siswa Kelas IV SDN Di Gugus V Kecamatan Tejakula Kabupaten Buleleng Tahun Pelajaran 2016/2017".

\section{Metode}

Artikel ini dibuat dari hasil penelitian semu dengan rancangan penelitian post-test only control group design. Penelitian ini dilaksanakan di SDN Gugus V Kecamatan Tejakula Kabupaten Buleleng dengan rentang waktu semester II (genap) pada tahun pelajaran 2016/2017. Populasi pada penelitian ini adalah seluruh siswa kelas IV di Gugus V Kecamatan Tejakula Kabupaten Buleleng tahun pelajaran 2016/2017. Banyak siswa seluruhnya 133 orang yang tersebar dalam 5 Sekolah Dasar yaitu SD Negeri 1, 2, 3 Pacung dan SD Negeri 1, 2 Julah. Total Populasi berjumlah berjumlah 133 orang yang terbagi menjadi 5 kelas. Sampel diambil dengan cararandom sampling yang berjumlah 64 orang terbagi menjadi dua kelas.

Data yang ingin diketahui dalam penelitian ini adalah hasil belajar siswa dalam mata pelajaran IPS. Metode pengumpulan data yang digunakan adalah tes obyektif pilihan ganda yang berjumlah 30 butir yang sudah divalidasi secara konten dan empirik. Secara konten, tes yang digunakan sudah memenuhi unsur kompetensi dasar dengan kalimat yang baik sesuai dengan perkembangan psikologis anak usia kelas IV Sekolah Dasar. Sedangkan analisis validasi empiriknya yang ditinjau dari analisis konsistensi internal tes terhadap 40 butir tes, 40 tes yang diujikan didapatkan 36 tes dinyatakan valid dan 4 tes dinyatakan tidak valid. Analisis daya beda butir tes didapatkan 11 butir yang berkualifikasi baik, 19 butir berkualifikasi cukup baik, dan 10 butir tes dinyatakan kurang baik. Analisis tingkat kesukaran tes didapatakan 18 butir tes berada pada kriteria mudah dan 20 butir tes berada kriteria sedang, dan 2 butir termasuk dalam kriteria sukar. Analisis reliabilitas tes menyatakan bahwa reliabilitas tes berada pada kualifikasi sangat tinggi $(0,88)$. Data hasil belajar IPS siswa diambil dengan memberikan post-test pada siswa setelah selesai menerapkan model pembelajaran kooperatif tipe Make A Match berbantuan media audio visual.

Hipotesis dalam penelitian ini dianalisis dengan menggunakan uji t. Namun untuk memberikan gambaran terhadap sebaran data penelitian ini menggunakan analisis deskriptif dengan kriteria rata-rata ideal dan standar deviasi ideal seperti pada Tabel 2 . 
Tabel 2. Kriteria Rata-rata Ideal dan Standar Deviasi Ideal

\begin{tabular}{ccc}
\hline Rentang Skor & Rentang Skor Real & Kategori \\
\hline $\mathrm{Mi}+1,5 \mathrm{SDi} \leq \mathrm{X} \leq \mathrm{Mi}+3,0 \mathrm{SDi}$ & $22,5 \leq \mathrm{X} \leq 30$ & Sangat tinggi \\
$\mathrm{Mi}+0,5 \mathrm{SDi} \leq \mathrm{X}<\mathrm{Mi}+1,5 \mathrm{SDi}$ & $17,5 \leq \mathrm{X}<22,5$ & Tinggi \\
$\mathrm{Mi}-0,5 \mathrm{SDi} \leq \mathrm{X}<\mathrm{Mi}+0,5 \mathrm{SDi}$ & $12,5 \leq \mathrm{X}<17,5$ & Sedang \\
$\mathrm{Mi}-1,5 \mathrm{SDi} \leq \mathrm{X}<\mathrm{Mi}-0,5 \mathrm{SDi}$ & $7,5 \leq \mathrm{X}<12,5$ & Rendah \\
$\mathrm{Mi}-3,0 \mathrm{SDi} \leq \mathrm{X}<\mathrm{Mi}-1,5 \mathrm{SDi}$ & $0 \leq \mathrm{X}<7,5$ & Sangat rendah \\
\hline
\end{tabular}

\section{Hasil Dan Pembahasan}

\section{Hasil Penelitian}

Penelitian ini menemukan bahwa pada kelompok eksperimen hasil belajar siswa setelah mengikuti pelajaran kooperatif tipe Make A Match berbantuan media audio visual sebanak 50,00\% siswa mendapatkan nilai dengan kategori sangat tinggi, $37,50 \%$ siswa mendapatkan nilai dengan kategori tinggi, $12,50 \%$ siswa mendapatkan nilai sedang dan 0,00\% siswa mendapat nilai dengan kategori rendah dan sangat rendah. Hasil berbeda didapatkan pada kelompok kontrol, yang mana pada kelompok kontrol hasil belajar setelah mengikuti pembelajaran yang secara naturaldilakukan oleh guru di sekolah sebanyak $43,38 \%$ siswa mendapatkan nilai yang termasuk kategori rendah dan sangat rendah, $28,13 \%$ siswa mendapatkan nilai yang termasuk kategori sedang dan $28,13 \%$ siswa mendapatkan nilai yang termasuk kategori tinggi dan sangat tinggi. Jadi secara deksriptif dapat dijelaskan bahwa, sebaran data dalam penelitian ini menunjukkan bahwa pada kelompok eksperimen data hasil belajar siswa cenderung berada pada katagori sedang ke atas, sedangkan pada kelompok kontrol cenderung berada pada kelompok sedang ke bawah.Lebih detail hasil post-test terhadap 32 orang siswa pada kelompok eksperimen dan terhadap 32 orang siswa kelompok kontrol ditunjukkan pada Tabel 3.

Tabel 3. Hasil post-test siswa kelompok eksperimen dan kontrol

\begin{tabular}{cccc}
\hline Rentang Skor Real & Kelompok Eksperimen & Kelompok Kontrol & Kategori \\
\hline $22,5 \leq \mathrm{X} \leq 30$ & $16(50,00 \%)$ & $3(9,38 \%)$ & Sangat tinggi \\
$17,5 \leq \mathrm{X}<22,5$ & $12(37,50 \%)$ & $6(18,75 \%)$ & Tinggi \\
$12,5 \leq \mathrm{X}<17,5$ & $4(12,50 \%)$ & $9(28,13 \%)$ & Sedang \\
$7,5 \leq \mathrm{X}<12,5$ & $0(0,00 \%)$ & $11(34,38)$ & Rendah \\
$0 \leq \mathrm{X}<7,5$ & $0(0,00 \%)$ & $3(9,00 \%)$ & Sangat rendah \\
\hline
\end{tabular}

Berdasarkan kriteria skala lima dan sesuai dengan hasil analisis data bahwa Mean hasil belajar IPS pada kelompok yang dibelajarkan dengan menggunakan model pembelajaran kooperatif tipe Make $A$ Match berbantuan media audio visual adalah 23,13 (berada pada kategori sangat tinggi). Sebaliknya Mean hasil belajar IPS pada kelompok yang dibelajarkan secara natural di sekolah adalah 15,00 (berada pada katagori sedang). Hal itu berarti bahwa nilai rata-rata hasil belajar IPS siswa kelompok eksperimen lebih tinggi dari pada nilai rata-rata hasil belajar IPS siswa kelompok kontrol. Data rata-rata dan standar deviasi hasil post-test kedua kelompok disajikan pada Tabel 4.

Tabel 4. Rerata dan Standar Deviasi Data Hasil Post-Test Kelompok Eksperimen dan Kontrol

\begin{tabular}{ccccc}
\hline Variabel & \multicolumn{2}{c}{ Kelompok Eksperimen } & \multicolumn{2}{c}{ Kelompok Kontrol } \\
\hline \multirow{2}{*}{ Post-test } & Rerata (mean) & Standar Deviasi & Rerata (mean) & Standar Deviasi \\
\cline { 2 - 5 } & 23,13 & 4,33 & 15,00 & 5,48 \\
\hline
\end{tabular}

Sebelum dilakukan pengujian hipotesis dengan uji $\mathrm{t}$ independent terlebih dahulu dilakukan pengujian terhadap prasyarat yang diperlukan terhadap sebaran data hasil penelitian. Uji prasyarat analisis meliputi dua hal, yaitu (1) uji normalitas distribusi data terhadap keseluruhan unit analisis, dan (2) uji homogenitas varian antar kelompok.

Uji normalitas data dilakukan pada keseluruhan unit analisis yaitu kelompok eksperimen dan kelompok kontrol. Analisis yang digunakan pada pengujian normalitas sebaran data adalah analisis Kolmogorov-Smirnov dan Shapiro-Wilk. Proses analisis dibantu dengan menggunakan program SPSS 16 for Windows. Ketentuan normalitas data ditentukan dengan melihat signifikansi hasil analisis. Data 
berdistribusi normal jika angka signifikansi yang diperoleh lebih dari 0,05 pada taraf signifikansi $5 \%$. Ringkasan hasil uji normalitas data pada kelompok eksperimen dan kelompok kontrol disajikan pada Tabel 5.

Tabel 5. Ringkasan Hasil Uji Normalitas Distribusi Data

\begin{tabular}{|c|c|c|c|c|c|c|}
\hline \multirow{2}{*}{ Kelompok } & \multicolumn{3}{|c|}{ Kolmogorov-Smirnov } & \multicolumn{3}{c|}{ Shapiro-Wilk } \\
\cline { 2 - 7 } & Statistic & df & Sig. & Statistic & df & Sig. \\
\hline Eksperimen & 0,111 & 32 & 0,200 & 0,962 & 32 & 0,315 \\
\hline Kontrol & 0,098 & 32 & 0,200 & 0,960 & 32 & 0,272 \\
\hline
\end{tabular}

Berdasarkan Tabel 5 dapat dijelaskan bahwa nilai signifikansi berada di atas 0,05 untuk semua unit analisis baik menggunakan statistik Kolmogorov-Smirnov maupun menggunakan statistik ShapiroWilk. Hal ini menunjukkan bahwa sebaran data pada kelompok eksperimen berdistribusi normal. Hasil yang hampir sama juga diperoleh pada data kelompok kontrol. Terungkap bahwa nilai signifikansi berada di atas 0,05 untuk semua unit analisis baik menggunakan statistik Kolmogorov-Smirnov maupun menggunakan statistik Shapiro-Wilk. Hal ini menunjukkan bahwa sebaran data pada kelompok kontrol juga berdistribusi normal.

Uji homogenitas varians dilakukan berdasarkan data hasil belajar IPS pada kelompok eksperimen dan kelompok kontrol. Jumlah masing-masing unit analisis adalah 32 dan 32 orang siswa. Uji homogenitas varians antar kelompok menggunakan uji $F$. Data dinyatakan homogen jika $F_{\text {hitung }}<F_{\text {tabel. }}$ Ringkasan hasil uji homogenitas varians antara kelompok disajikan dalam Tabel 6.

Tabel 6. Ringkasan Hasil Uji Homogenitas Varians dengan Uji F

\begin{tabular}{ccccccc}
\hline Sampel & Mean & SD & Varians & Fhitung & Ftabel & Kesimpulan \\
\hline Kelompok eksperimen & 23,13 & 4,33 & 18,72 & \multirow{2}{*}{1,60} & \multirow{2}{*}{1,82} & Fhitung $<$ Ftabel \\
\cline { 1 - 3 } Kelompok kontrol & 15,00 & 15,48 & 30,00 & & \\
\hline
\end{tabular}

Berdasarkan Tabel 6 ringkasan data hasil uji homogenitas varians untuk kedua kelompok model pembelajaran menunjukkan bahwa $\mathrm{F}_{\text {hitung }}<\mathrm{F}_{\text {tabel }}$ yang dibantu dengan program Microsoft Excel 2007 for Windows. Ini berarti bahwa varians antara kelompok siswa homogen.

Hipotesis penelitian yang diuji adalah terdapat perbedaan hasil belajar IPS antara siswa yang mendapat perlakuan model pembelajaran kooperatif tipe Make A Match berbantuan media audio visual dan siswa yang mendapat perlakuan tidak dengan model pembelajaran kooperatif tipe Make A Match berbantuan media audio visual. Untuk menguji hipotesis yang diajukan digunakan uji-t tidak berkorelasi atau $t$-test independent. Tabel 6 menunjukkan bahwa varian homogen dan jumlah siswa pada tiap kelas yang sama maka pada uji-t tidak berkorelasi ini digunakan rumus polled varians. Ringkasan hasil uji-t tidak berkorelasi disajikan pada Tabel 7 .

Tabel 7. Ringkasan Data Hasil Uji Hipotesis

\begin{tabular}{|c|c|c|c|c|c|c|}
\hline Kelompok & Varian & $\mathrm{N}$ & $\mathrm{db}$ & thitung & ttabel & Kesimpulan \\
\hline Kelompok Eksperimen & 18,72 & 32 & 62 & 6775 & 1909 & thitung $>$ ttabe \\
\hline Kelompok Kontrol & 30,00 & 32 & 62 & $0, / 15$ & 1,999 & H1 diterima \\
\hline
\end{tabular}

Berdasarkan hipotesis penelitian yang telah diajukan pada kajian teori kriteria pengujian $\mathrm{H}_{0}$ ditolak jika thitung $>t_{\text {tabel }}$ dan $\mathrm{H}_{1}$ diterima, dengan taraf signifikansi $5 \%$ dan didukung oleh perbedaan skor rata-rata yang diperoleh antara kelompok eksperimen yaitu 23,13 yang berada pada kategori sangat tinggi dan kelompok kontrol yaitu 15,00 yang berada pada kategori sedang (cukup tinggi) maka hipotesis alternatif diterima. Ringkasan data hasil uji hipotesis menunjukan hal yang sama bahwa $t_{\text {hitung }}>t_{\text {tabel }}$ sehingga $\mathrm{H}_{0}$ ditolak dan $\mathrm{H}_{1}$ diterima. Dengan demikian dapat diinterpretasikan bahwa terdapat perbedaan terdapat perbedaan yang signifikan hasil belajar IPS antara siswa kelas IV yang diberi perlakuan dengan model pembelajaran Make a Match berbantuan media audio visual dan siswa yang diberi perlakuan tidak dengan model pembelajaran Make a Match berbantuan media audio visual di Kelas IV SD Gugus V Kecamatan Tejakula Kabupaten Buleleng Tahun Pelajaran 2016/2017.

\section{Pembahasan}

Hasil Penelitian ini menemukan bahwa terdapat perbedaan hasil belajar IPS antara kelompok siswa yang diberi perlakuan dengan model pembelajaran kooperatif tipeMake a Match berbantuan media audio visual dan siswa yang diberi perlakuan tidak dengan model pembelajaran kooperatif tipe Make a Match berbantuan media audio visual. Secara deskriptif, hasil belajar IPS siswa kelompok eksperimen 
lebih tinggi dibandingkan dengan siswa kelompok kontrol. Tinjauan ini didasarkan pada rata-rata skor hasil belajar IPS dan kecenderungan skor hasil belajar IPS. Rata-rata skor hasil belajar IPS siswa kelompok eksperimen adalah 23,28 yang berada pada kategori sangat tinggi. Sementara itu, skor hasil belajar IPS siswa kelompok kontrol adalah 15,00 yang berada pada kategori sedang. Jadi itu berarti bahwa model pembelajaran kooperatif tipe Make A Match berbantuan media audio visual berpengaruh positif terhadap hasil belajar IPS siswa kelas IV SDN di Gugus V Kecamatan Tejakula Kabupaten Buleleng Tahun Pelajaran $2016 / 2017$.

Hasil penelitian ini menunjukkan bahwa pada kelompok siswa setelah mengikuti pelajaran kooperatif tipe Make A Match berbantuan media audio visual sebanak 50,00\% siswa mendapatkan nilai dengan kategori sangat tinggi, 37,50\% siswa mendapatkan nilai dengan kategori tinggi, $12,50 \%$ siswa mendapatkan nilai sedang dan $0,00 \%$ siswa mendapat nilai dengan kategori rendah dan sangat rendah. Adanya variasi ini menunjukkan bahwa hasil belajar siswa tidak hanya dipengaruhi oleh faktor model pembelajaran yang diberikan oleh guru saja. Hasil wawancara dengan siswa menyatakan bahwa faktor lain yang diduga juga ikut menjadi pengaruh yaitu faktor sarana dan prasarana pembelajaran, rasa percaya diri siswa, motivasi belajar, bakat yang dimiliki siswa, keadaan ekonomi siswa, manajemen sekolah, dan iklim sekolah. Hal ini menguatkan teori yang menyatakan bahwa faktor-faktor yang mempengaruhi prestasi belajar dapat digolongkan ke dalam dua golongan yaitu faktor intern yang bersumber pada diri siswa dan faktor ekstern yang bersumber dari luar diri siswa (Waslimandalam Susanto, 2013).

Perbedaan hasil belajar antara siswa yang diberi perlakuan dengan model pembelajaran Make a Match berbantuan media audio visual dan siswa yang tidak diberi perlakuan dengan model pembelajaran Make a Match berbantuan media audio visual disebabkan adanya perbedaan perlakuan pada proses pembelajaran. Hal ini terjadi karena model kooperatif tipe make a match berbantuan media audio visual merupakan salah satu model pembelajaran yang dapat memberikan kesempatan kepada siswa belajar dengan kreatif dan inovatif. Dengan dukungan media audio visual (video) lengkap rasanya pembelajaran yang menyenangkan didapat siswa, berbagai hal positif didapatkan siswa dari pembelajaran menggunakan model kooperatif tipe make a match berbantuan audio visual salah satunya adalah hasil belajar yang bagus.

Menurut Huda dalam (Riadi, 2015), model pembelajaran kooperatif tipe make a matchmerupakan model pembelajaran yang melibatkan para siswa dalam mereview bahan yang tercakup dalam pelajaran dan mengecek atau memeriksa pemahaman siswa mengenai isi pelajaran dengan memberikan masingmasing siswa sebuah kuis yang berisi pertanyaan dan jawaban. Dalam pembelajaran IPS menggunakan model pembelajaran kooperatif tipe make a match berbantuan media audio visual memungkinkan siswa dapat bekerja sama dengan pasangannya dimana siswa saling berbagi informasi secara kebersamaan. Dalam pembelajaran ini siswa dilatih untuk mengembangkan kerjasama untuk dapat pemecahan permasalahan materi yang diberikan oleh guru dalam pembelajaran. Selain itu kehadiran media audio visual (video) menambah beragamnya sumber belajar siswa. Kelebihan dari model pembelajaran kooperatif tipe make a match: 1) Mampu menciptakan suasana belajar aktif dan menyenangkan. 2) Materi pembelajaran yang disampaikan lebih menarik perhatian siswa. 3) Suasana kegembiraan akan tumbuh dalam proses pembelajaran. 4) Kerjasama antar sesama siswa terwujud dengan dinamis. 5) Munculnya dinamika gotong royong yang merata di seluruh siswa. Keunggulan dari model ini adalah siswa mencari pasangan sambil belajar mengenai suatu konsep atau topic dalam suasana yang menyenangkan (Lie, 2008).

Model pembelajaran kooperatif tipe make a match sangat berbeda dengan model pembelajaran yang biasa diterapakan oleh guru-guru di sekolah. Perbedaan ini terlihat dari sintaks dan metode yang digunakan dalam proses pembelajaran. Model pembelajaran yang biasa dipakai ol eh guru lebih cenderung guru yang aktif dalam proses pembelajaran, guru mentransfer begitu saja pengetahuan yang dimiliki kepada peserta didik tanpa memperhitungkan mental peserta didik (Rasana, 2009). Kondisi seperti ini, mengakibatkan siswa pasif dalam pembelajaran di kelas dan cenderung akan cepat merasa bosan. Berbeda halnya dengan model pembelajaran kooperatif tipe make a match, dalam proses pembelajarannya siswa diberikan kesempatan untuk aktif dalam kegiatan pembelajaran melaui permainan mencari pasangan. Mulai dari kegiatan mengeksplorasi pengetahuan awal dan pengalaman siswa dengan bantuan media audio visual (video), melakukan permaianan mencari pasangan, dan merangkum proses pembelajaran yang telah dilaksanakan. Proses pembelajaran seperti inilah yang diinginkan oleh peserta didik, mereka diberikan kebebasan untuk mengeksplor kemampuan yang mereka miliki. Jadi sudah dapat dilihat proses pembelajaran dengan yang tidak diberi perlakuan model pembelajaran kooperatif tipe make a match membuat siswa cenderung pasif yang akan berpengaruh pada perolehan hasil belajar. 
Hasil penelitian ini menguatkan beberapa hasil penelitian yang ditemukan belakangan ini diantaranya penelitian yang dilakukan Suatnaya (2015) bahwa model pembelajaran kooperatif tipe Make A Match berpengaruh terhadap hasil belajar siswa. Hasil penelitian lain oleh Johnson D.W, Roger T, dan Stanne Mary Beth (2000) menemukan bahwa model pembelajaran kooperatif dapat berpengaruh terhadap prestasi belajar siswa. Hasil penelitian Ebrahim Ali (2012) menemukan bahwa pembelajaran kooperatif memiliki pengaruh yang signifikan terhadap prestasi siswa. Hasil penelitian Alabekee E. C., Samuel A., Dkk (2015), menemukan bahwa pembelajaran kooperatif memungkinkan peserta didik untuk meneria umpan balik positif dan meningkatkan hasil prestasi akademik siswa. Hasil Penelitian Tran Van Drat (2014) menemukan bahwa pembelajaran kooperatif mencapai nilai yang secara signifikan lebih tinggi. Sejalan dengan penelitian yang dilakukan Gull F., Shehzad S. (2015) menemukan bahwa model pembelajaran kooperatif dapat meningkatkan prestasi belajar siswa. Dan penelitian yang dilakukan Ajaja Patrick, Eravwoke Ochuko Urhievwejire (2010) menunjukkan bahwa pembelajaran kooperatif meningkatkan prestasi belajar siswa. Penelitian yang dilakukan Mehta Sohnam dan Kulshrestha A. K (2014) menemukan bahwa penerapan model pembelajaran kooperatif meningkatkan hasil belajar siswa. Hasil Penelitian yang dilakukan Najmonnisa, Mirza Amin ul Haq, Ismail Saad (2015) menemukan bahwa pembelajaran kooperatif meningkatkan prestasi akademik siswa. Penelitian yang dilakukan Pandey N. N. dan Kishore Kaushal (2003), Bukunola1, B. A., Idowu Oludipe Daniel (2012), Zakaria, E., Solfitri, T., Daud, Y. \& Abidin, Z. (2013), Colak, E. (2015), Nawaz Qayyum, Hussain Liaquat, Abbas Asif , Javed Muhammad (2014)menemukan bahwa pembelajaran kooperatif berpengaruh terhadap hasil belajar siswa.

\section{Simpulan Dan Saran}

Berdasarkan hasil pengujian hipotesis dan pembahasan, maka simpulan penelitian ini yaitu terdapat perbedaan hasil belajar IPS antara kelompok siswa yang diberi perlakuan menggunakan model pembelajaran Make A Match berbantuan media Audio Visual dengan kelompok siswa yang tidak diberi perlakuan menggunakan model pembelajaran Make A Match berbantuan media Audio Visual pada siswa kelas IV Kecamatan Tejakula Kabupaten Buleleng Tahun Pelajaran 2016/2017. Rata-rata skor hasil belajar IPS kelompok siswa yang diberi perlakuan menggunakan model pembelajaran Make A Match berbantuan media Audio Visual adalah 23,28 sedangkan rata-rata skor kelompok siswa yang tidak diberi perlakuan menggunakan model pembelajaran Make A Match berbantuan media Audio Visual adalah 15,00. Dengan demikian model pembelajaran koperatif tipe Make A Match ini memiliki pengaruh yang signifikan terhadap hasil belajar IPS. Penelitian ini memberikan kontribusi positif terhadap perkembangan keilmuan terutama dibidang pembelajaran IPS. Oleh karena itu disarankan kepada guru-guru yang mengajar materi IPS hendaknya menggunakan model pembelajaran kooperatif tipe Make A Match berbantuan media audio visual sebagai salah satu alternatif pembelajaran IPS agar pembelajaran langsung lebih afektif. Penelitian ini juga dapat dijadikan refrensi untuk melakukan penelitian lebih lanjut dengan materi atau pokok bahasan yang berbeda, tingkat kelas yang berbeda, dan tambahan variabel baru sebagai kreativitas baru.

\section{Daftar Pustaka}

Ajaja, Patrick., Eravwoke O.U. 2010. "Effects of Cooperative Learning Strategy on Junior Secondary School Students Achievement in Integrated Science". Electronic Journal of Science Education. Vol. 14, No. 1. Tersedia Pada: http://ejse.southwestern.edu/article/view/7323/5617. Diakses, 28 Mei 2017.

Alabekee E. C., Samuel A., Dkk. "Effect Of Cooperative Learning Strategy On Students Learning Experience And Achievements In Mathematics". International Journal of Education Learning and Development. 3(4): 67-75. Tersedia pada: www.eajournals.org. Diakses, pada tanggal 28 mei 2017.

Bukunola1, B. A., Idowu Oludipe Daniel. 2012. "Effectiveness of Cooperative Learning Strategies on Nigerian Junior Secondary Students' Academic Achievement in Basic Science”. British Journal of Education, Society \& Behavioural Science. Vol. 2(3): 307-325. Tersedia Pada: http://www.sciencedomain.org/abstract/664.Diakses, 2 Juni 2017.

Colak, E. (2015). "The Effect of Cooperative Learning on the Learning Approachhes of Students with Different Learning Styles". Eurasian Journal of Educational Research. Vol. 59, 17-34. Tersedia Pada:http://dx.doi.org/10.14689/ejer.2015.59.2. Diakses, 2 Juni 2017.

Ebrahim, Ali. 2012. "The Effect Of Cooperative Learning Strategies On Elementary Students Science Achievement and Social Skill in Kuwait". International Journal of Science and Mathematics Education. $\quad$ Vol. 10(2):293-314. Tersedia Pada: https://link.springer.com/article/10.1007\%2Fs10763-011-9293-0. Diakses, 28 Mei 2017. 
Gull F., Shehzad S. (2015). "Effects of Cooperative Learning on Students' Academic Achievement". Journal of Education and Learning. Vol. 9(3) pp. 246-255. Tersedia Pada: http://journal.uad.ac.id/index.php/EduLearn/article/view/2071. Diakses, 28 Mei 2017.

Hasbullah. 2012. Dasar-dasar Ilmu Pendidikan. Jakarta: PT. Raja Grafindo Persada.

Johnson D.W., Roger T., Stanne M.B. 2000. “Cooperative Learning Methods: A Meta-Analisis". Tersedia Pada:

https://pdfs.semanticscholar.org/93e9/97fd0e883cf7cceb3b1b612096c27aa40f90.pdf. Diakses, 28 Mei 2017.

Lie, Anita. 2008. Cooperative Learning Mempraktikkan Cooperative Learning Di Ruang-Ruang Kelas. Jakarta: Grasindo.

Mehta Sohnam., Kulshrestha A. K. (2014). Implementation of Cooperative Learning in Science: A Developmental-cum-Experimental Study. Hindawi Publishing Corporation Education Research International. $\quad$ Vol. $\quad 6.2014 .62$ Tersedia https://www.hindawi.com/journals/edri/2014/431542/. Diakses, 2 Juni 2017

Najmonnisa, Mirza Amin ul Haq, Ismail Saad. 2015. "Impact of Cooperative Learning Teaching Methods on 7th Grade Students Academic Achievement: An Experimental Study". Journal of Elementary Education. Vol.25, No. 2 pp. 89-112. Tersedia Pada:

http://pu.edu.pk/images/journal/JEE/PDF Files/6 Najmonnisa\%2025(II).pdf. Diakses, 2 Juni 2017.

Nawaz Qayyum, Hussain Liaquat, AbbasAsif, Javed Muhammad. 2014. "EFFECT OF COOPERATIVE LEARNING ON THE ACADEMIC ACHIEVEMENT AND SELF CONCEPT OF THE STUDENTS AT ELEMENTARY SCHOOL LEVEL". Gomal University Journal of Research. Vol. 30(2). Tersedia Pada: http://www.gu.edu.pk/New/GUIR/PDF/PDF\%20DEC 2014/17Effect\%20of\%20cooperative\%20 learning.pdf. Diakses, 2 Juni 2017.

Pandey N. N., Kishore Kaushal. 2003. "EFFECT OF COOPERATIVE LEARNING ON COGNITIVE ACHIEVEMENT IN SCIENCE". JOURNAL OF SCIENCE AND MATHEMATICS EDUCATION IN S.E. ASIA. Vol. 26, No. 2. Tersedia Pada: http://www.recsam.edu.my/R\&D Journals/YEAR2003/52-60.pdf. Diakses, 2 Juni 2017.

Rasana, Raka. 2009. Model-model Pembelajaran. Singaraja: DIPA PNBP FIP Undiksha.

Riadi, Muchlisin. 2015. "Model Pembelajaran Tipe Make a Match". Tersedia Pada: http://www.kajianpustaka.com/2015/03/model-pembelajaran-tipe-make-match.html. Diakses, 16 Januari 2017.

Rusman. 2012. Model-model Pembelajaran. Jakarta: PT. Raja Grafinda Persada.

Suatnaya, I Putu Mas. 2015. "Pengaruh Model Pembelajaran Kooperatif Make a Match Berbantuan Media Benda Asli Terhadap Hasil Belajar Matematika Siswa Kelas IV SD Negeri Pemaron Tahun Pelajaran 2014/2015”. Jurnal PGSD Universitas Pendidikan Ganesha. Vol. 3 No. 1 Tahun 2015. (online). Tersedia Pada:

http://ejournal.undiksha.ac.id/index.php/JPGSD/article/download/5677/4130. Diakses, 16 Januari 2017.

Sugiyono. 2011. Metode Penelitian Kuantitatif, Kualitatif dan R\&D. Bandung: Alfabeta.

Susanto, Ahmad. 2013. Teori Belajar dan Pembelajaran di Sekolah Dasar. Yogyakarta: Pustaka Belajar.

Tjandra, dkk. 2005. Pendidikan Ilmu Penetahuan Sosial di Sekolah Dasar. Singaraja: Undiksha.

Tran Van Dat. 2014. "The Effects of Cooperative Learning on the Academic Achievement and Knowledge Retention". International Journal of Higher Education.Vol. 3(2). Tersedia Pada: http://www.sciedu.ca/ijhe. Diakses 28 Mei 2017.

Wati, Ega Rima. 2016. Ragam Media Pembelajaran. Yogyakarta: Kata Pena.

Zakaria, E., Solfitri, T., Daud, Y. \& Abidin, Z. 2013. "Effect of Cooperative Learning on Secondary School Students' Mathematics Achievement". Creative Education, Vol. 4, 98-100. Tersedia Pada: http://dx.doi.org/10.4236/ce.2013.42014. Diakses, 2 Juni 2017 